\title{
Unilateral thyroid swelling due to actinomycosis
}

\author{
S. Arfeen, M.T. Boast and D.M. Large \\ Department of Medicine, Cumberland Infirmary, Carlisle CA2 7HY, UK.
}

\begin{abstract}
Summary: A case of unilateral thyroid swelling due to actinomycosis in a 27 year old farm worker is described. Diagnosis was made by fine needle biopsy under ultrasound control.
\end{abstract}

\section{Introduction}

Unilateral thyroid swellings due to bacterial infections are uncommon and infection by actinomycosis is even more rare. We describe here a case of recurrent thyroid enlargement due to actinomycosis diagnosed by fine needle aspiration biopsy under ultrasound control.

\section{Case report}

A 27 year old farm worker presented with a 3-week history of a slightly tender swelling, $1.5 \mathrm{~cm}$ in diameter within the upper part of the right lobe of the thyroid. The overlying skin was normal, there was no lymphadenopathy and he was euthyroid. There were several carious teeth and chronic marginal gingivitis. Investigations showed white cell count $4.0 \times 10^{9} / 1$, serum thyroxine $116 \mathrm{nmol} / 1$ (normal range $50-160 \mathrm{nmol} / \mathrm{l}$ ), thyroid antibodies negative. Ultrasound examination of the neck showed a slightly enlarged right lobe of the thyroid but no discrete lesion, and a technetium $-99 \mathrm{~m}$ isotope scan showed uniform uptake throughout the thyroid. Within 2 weeks, all symptoms and signs had resolved without treatment.

Four months later, a more extensive swelling developed within and around the right lobe of the thyroid, progressing over 3 weeks. There was marked induration and reddening of the overlying skin, and the right lobe of the thyroid felt greatly enlarged and firm and moved on swallowing. There was, however, minimal local discomfort. Further investigations showed erythrocyte sedimentation rate $17 \mathrm{~mm}$ in the first hour. White cell count $5.8 \times 10^{9} / 1$; thyroid antibodies negative, chest X-ray normal. Ultrasound of the neck showed a greatly enlarged right lobe of thyroid with numerous echo-dense areas suggesting fluid and oedema within the thyroid. Technetium scan showed uniform uptake with enlargement of the right

Correspondence: D.M. Large, M.D., M.R.C.P.

Accepted: 20 February 1986 lobe of the thyroid. Aspiration biopsy was performed under ultrasound control. Histology and cytology showed colonies of branching Gram-positive filaments typical of actinomycosis, with a small round cell infiltration. Areas of thyroid epithelium were present on a second aspirate taken from an immediately adjacent area. Ziehl-Nielson stain was negative. Bacteriological culture of this material was unsuccessful, and specimens from the mouth showed no evidence of actinomycosis.

Procaine penicillin $1.2 \mathrm{~g}$ /day, was given intramuscularly for 2 weeks followed by phenoxymethylpenicillin $2 \mathrm{~g} /$ day, with probenecid $1 \mathrm{~g} /$ day by mouth, for a further 4 weeks. Within this time, the skin and the right lobe of the thyroid returned to normal. The patient has since had dental treatment in case the mouth was the portal of entry of infection. There has been no evidence of recurrent infection during the 12 months of follow-up.

\section{Discussion}

Actinomycosis of the thyroid gland is an extremely rare condition with few documented cases (Leers et al., 1969; Blanc \& Jenny, 1974; Volpé, 1978). Diagnosis on clinical grounds would have been difficult, but the slow progression, lack of pyrexia, the relatively painless induration and swelling, together with the normal white cell count and erythrocyte sedimentation rate, did not suggest a simple pyogenic bacterial infection. Ultrasound-guided aspiration led to a rapid diagnosis and treatment. Thyroid function and isotope uptake remained normal, contrasting with previous reports in which reduced uptake in affected areas has been described (Leers et al., 1969; Blanc \& Jenny, 1974; Cobo et al., 1983). Evidently in our case, abscess formation did not occur, despite the oedematous appearance of the thyroid at ultrasound examination. A long natural history is characteristic of this infection, so it is possible that the first episode of thyroid 
swelling was also related to infection with actinomycosis. The precise strain of the organism remains unknown, although thyroiditis following infection with Actinomyces israeli, bovis and naeslundi have all been described (Leers et al., 1969). The portal of entry was probably the mouth, particularly with his dental neglect, and his farming occupation may also have contributed, although actinomycosis is an unusual cause of infection even in this rural area (Dr M.A. Knowles, personal communication).

Actinomycotic thyroiditis has also been described in

\section{References}

BLANC, E. \& JENNY, M. (1974). Tyroidite à actinomycose. Schweizerische Medizinische Wochenschrift, 31, 1094.

COBO, C.M.J., LOPEZ, P.B., JIMENEZ, F.P., RUBIO, F.L. \& PEREPEREZ, J.A.J. (1983). Actinomycosis tiroidea. Medicina Clinica (Barcelona), 80 (2), 93.

LEERS, W.D., DUSSAULT, J., MULLENS, J.E. \& VOLPE, R. (1969). Suppurative thyroiditis: an unusual case caused by Actinomyces naeslundi. Canadian Medical Association Journal, 101, 714. a child where transmission of the infection down the thyroglossal duct was suggested (Zemen et al., 1980). There was nothing to suggest this mechanism in the present case.

\section{Acknowledgements}

We thank Dr R.H. McNeil for the ultrasound examination, and Dr E.D. Long and Dr M.A. Knowles for helpful discussion of the pathological and bacteriological material.

VOLPE, R. (1978). The pathology of thyroiditis. Human Pathology, 9, 429.

ZEMEN, V., SMEJKAL, V. \& NAHODIL, V. (1980). Actinomycosis of thyroid gland in an 8 year old girl. Role of thyroglossal duct in pathogenesis. Ceskoslovenská Pediatrie, 35, 224. 